\title{
Mitral valve sub valvular apparatus preservation in pure or predominant rheumatic mitral stenosis
}

\author{
Abdelmalek Bouzid", Salim Chibane, Mohamed Atbi, Halima Larbi, Boukri Hamouda, Redha Djilali-Sayeh, \\ Youcef Larabi, Tarek Hamdi, Sami Bouchenafa, Ramdan A Ould Abderrahmane \\ From World Society of Cardiothoracic Surgeons 25th Anniversary Congress, Edinburgh \\ Edinburgh, UK. 19-22 September 2015
}

\section{Background/Introduction}

Surgery of the mitral valve is an important part of the surgical activity at Algerian heart surgery departments.

In many cases the lesions exceed the possibility of native valve preservation, thus requiring the replacement thereof.

When replacing, conservation of the subvalvular apparatus or not remains a question which had a real interest, which was reflected in the significant number of studies on the subject.

The majority of these studies have demonstrated the value of subvalvular apparatus preservation on the future of ventricular function in the immediate and distant; however almost all of these studies have concerned patients with mitral insufficiency lesions.

\section{Aims/Objectives}

Our aim is to evaluate the impact of mitral valve subvalvular apparatus preservation on left ventricular function after valve replacement in patient with predominant or pure mitral stenosis

\section{Method}

77 patients underwent a mitral valve replacement for mitral valve stenosis, 54 patients (group1) had no preservation, 23 patients (group 2) had partial sub valvular preservation; there were no significant differences between the two groups in pre-operative parameters (age, sex, functional status, AF, LVEDD, LVESD, LVEF).

The mean follow up was 19 months.

\section{Results}

In all of the postoperative study parameters, no significant difference was found between groups either in terms of mortality, left or right ventricular function, LVEF

Department of Cardiac Surgery, EHU 1er Novembre 54, Oran 31000, Algeria
$(62.98+/-2.65 \%$ vs $61+/-4.20 \%)$; LVEDD $(47.3+/-$ $1.4 \mathrm{~mm}$ vs $46.1+/-2.6 \mathrm{~mm})$; LVESD $(30.8+/-1.7 \mathrm{~mm}$ vs $30.9+/-2.6 \mathrm{~mm})$; TAPSE $(15.78+/-0.88 \mathrm{~mm}$ vs $15.65+/-$ $1.0 \mathrm{~mm})$, Sa $(10.58+/-0.47 \mathrm{~cm} / \mathrm{s}$ vs $10.35+/-0.77 \mathrm{~cm} / \mathrm{s})$ respectively for group 1 and group 2 .

\section{Discussion/Conclusion}

The short- and medium-term results of our study did not demonstrate the interest of preserving the sub valvular apparatus in mitral valve replacement surgery on pure or predominant rheumatic mitral stenosis; however a longer follow-up is need to evaluate the impact on either left or right ventricular function.

Published: 16 December 2015

doi:10.1186/1749-8090-10-S1-A2

Cite this article as: Bouzid et al:: Mitral valve sub valvular apparatus preservation in pure or predominant rheumatic mitral stenosis. Journal of Cardiothoracic Surgery 2015 10(Suppl 1):A2.

Submit your next manuscript to BioMed Central and take full advantage of:

- Convenient online submission

- Thorough peer review

- No space constraints or color figure charges

- Immediate publication on acceptance

- Inclusion in PubMed, CAS, Scopus and Google Scholar

- Research which is freely available for redistribution

Submit your manuscript at www.biomedcentral.com/submit 